\title{
TEOREMA TITIK TETAP BERKAITAN DENGAN PEMETAAN KONTRAKSI-F DAN JARAK- $\omega$ PADA RUANG METRIK LENGKAP
}

\section{Fixed Point Theorems Relates to Mapping F-Contraction and w-Distance in Complete Metric Spaces}

\author{
Irvandi Gorby Pasangka ${ }^{1 *}$ \\ ${ }^{1}$ Program Studi Matematika, Fakultas Sains dan Teknik, Universitas Nusa Cendana \\ Jl. Adisucipto, Kupang, 85001, Indonesia
}

Corresponding author e-mail: $1 *$ irvandi.p@staf.undana.ac.id

\begin{abstract}
Abstrak
Dalam tulisan ini, akan dibahas mengenai teorema titik tetap yang lebih umum dari teorema titik tetap untuk pemetaan kontraksi- $F$ pada ruang metrik lengkap. Pada teorema yang dibahas, ruang yang digunakan adalah ruang metrik lengkap dan menggunakan konsep jarak- $\omega$. Pemetaan yang digunakan adalah pemetaan tipe Hardy-Roger kontraksi- $F$ dengan mengambil $L=0$. Eksistensi titik tetap untuk pemetaan ini dijamin dengan memberikan syarat tambahan, di mana syarat ini akan selalu berlaku jika yang digunakan adalah metrik. Karena setiap jarak- $\omega$ adalah metrik, maka dari teorema yang dihasilkan akan berlaku juga jika yang digunakan adalah metrik. Dari teorema yang dibuktikan, diperoleh beberapa akibat di antaranya adalah teorema-teorema yang telah dibuktikan dalam jurnal lain.
\end{abstract}

Kata Kunci : Titik tetap, kontraksi-F, jarak- $\omega$.

Abstract

In this paper, it will be discussed the more common fixed point theorems than fixed point theorem for $F$-contractive mappings in complete metric spaces. On the theorem that was discussed, the concept of $\omega$-distance plotted on the complete metric spaces. The mapping used was a mapping Hardy-Roger-type F-contraction by taking L=0. The existence of a fixed point for this mapping is guaranteed by providing additional conditions, where this requirement will always apply if it is used as a metric. Because every $\omega$-distance is a metric, than any theorem produced would apply as well if that was used a metric. From the proven theorems, obtained several consequences among which are the theorems which have been proven in other journals.

Keywords: fixed point, F-contraction, $\omega$-distance.

Submitted: $21^{\text {th }}$ January $2021 \quad$ Accepted: $25^{\text {th }}$ May 2021

How to cite this article:

I. G. Pasangka, "TEOREMA TITIK TETAP BERKAITAN DENGAN PEMETAAN KONTRAKSI- $F$ DAN JARAK- $\omega$ PADA RUANG METRIK LENGKAP”, BAREKENG: J. Il. Mat. \& Ter., vol. 15, no. 02, pp. 355-360, Jun. 2021. 


\section{PENDAHULUAN}

Teori titik tetap adalah salah satu penelitian dalam bidang matematika analisis yang memiliki cukup banyak aplikasi. Salah satu aplikasi teori tersebut adalah untuk membuktikan eksistensi penyeleseaian suatu sistem persamaan diferensial. Teori titik tetap berawal dari ditemukannya Prinsip Kontraksi Banach pada tahun 1922. Banyak peneliti mulai mengembangkan teori titik tetap dengan cara membuat jenis pemetaan yang berbeda dan mengubah ruang pembicaraannya, di antaranya adalah Wardowski [15] yang mengenalkan kontraksi- $F$, dilanjutkan dengan Batra dan Vashishta [4] yang memperumum pemetaan kontraksi- $F$. Kemudian pada tahun 2014, Cosentino [6] yang membuktikan eksistensi titik tetap untuk pemetaan tipe Hardy-Roger kontraksi- $F$, dilanjutkan dengan Popescu dan Stan [11] yang memperumum teorema yang diberikan Cosentino.

Pada tahun 1996, Kada, Suzuki dan Takahashi [8] memperkenalkan konsep jarak- $\omega$ pada ruang metrik. Berbagai teorema titik tetap sudah banyak dikembangkan dengan menggunakan konsep jarak- $\omega$. Setiap metrik merupakan jarak- $\omega$, tetapi sebaliknya belum tentu berlaku, dengan kata lain jarak- $\omega$ lebih umum daripada metrik. Dengan menggunakan konsep jarak- $\omega$ pada pemetaan tipe Hardy-Roger kontraksi$F$, maka teorema titik tetap yang akan dihasilkan pun menjadi lebih umum, namun dalam tulisan ini diambil $L=0$ agar eksistensi titik tetapnya terjamin. Dengan memperumum teorema dengan konsep jarak- $\omega$, diharapkan aplikasi yang dihasilkan pun semakin luas.

\section{METODE PENELITIAN}

Metode penelitian yang dipakai adalah metode studi literatur. Dalam penelitian ini, dilakukan perubahan-perubahan pada beberapa teorema-teorema yang sudah ada sehingga membuatnya menjadi lebih umum dari teorema sebelumnya. Berdasarkan konsep jarak- $\omega$ yang diberikan oleh Kada, Suzuki, dan Takahashi [8], diketahui bahwa jarak- $\omega$ lebih umum daripada metrik, artinya semua metrik merupakan jarak- $\omega$, tetapi sebaliknya belum tentu benar, sehingga jika digunakan konsep jarak- $\omega$ pada suatu teorema yang menggunakan metrik, maka akibatnya teorema tersebut akan menjadi lebih umum.

\section{HASIL DAN PEMBAHASAN}

Definisi dari jarak- $\omega$ yang diberikan oleh Kada, Suzuki, dan Takahashi [8] adalah sebagai berikut.

Definisi 1. Diberikan ruang metrik $(X, d)$. Fungsi $q: X \times X \rightarrow[0, \infty)$ disebut jarak- $\omega$ pada $X$ jika memenuhi:
a. $q(u, z) \leq q(u, v)+q(v, z), \forall u, v, z \in X$,
b. untuk setiap $u \in X, q(u, \cdot): X \rightarrow[0, \infty)$ fungsi semikontinu bawah,
c. untuk setiap $\varepsilon>0$ terdapat $\delta>0$ sehingga $\forall u, v, z \in X$ dengan $q(z, u) \leq \delta$ dan $q(z, v) \leq \delta$ berakibat $d(u, v) \leq \varepsilon$,

Setiap metrik merupakan jarak- $\omega$, tetapi sebaliknya belum tentu benar. Berikut diberikan sifat-sifat mengenai jarak- $\omega$ yang akan digunakan dalam pembuktian teorema titik tetap terkait jarak- $\omega$.

Lemma 2. Misalkan $(X, d)$ ruang metrik dan q jarak- $\omega$ pada $X$. Jika $\left\{u_{n}\right\}$, $\left\{v_{n}\right\}$ barisan di $X$ dan $\left\{\alpha_{n}\right\},\left\{\beta_{n}\right\} \subseteq[0, \infty)$ konvergen ke 0 , serta $u, v, z \in X$ maka pernyataan-pernyataan berikut berlaku:

a. Jika $q\left(u_{n}, v\right) \leq \alpha_{n}$ dan $q\left(u_{n}, z\right) \leq \beta_{n}$ untuk setiap $n \in \mathbb{N}$ maka $v=z$, lebih lanjut, jika $q(u, v)=0$ dan $q(u, z)=0$ maka $v=z$.

b. Jika $q\left(u_{n}, v_{n}\right) \leq \alpha_{n}$ dan $q\left(u_{n}, z\right) \leq \beta_{n}$ untuk setiap $n \in \mathbb{N}$ maka $\lim _{n \rightarrow \infty} v_{n}=z$.

c. Jika $q\left(u_{n}, u_{m}\right) \leq \alpha_{n}$ untuk setiap $n, m \in \mathbb{N}$ dengan $m>n$ maka $\left\{u_{n}\right\}$ barisan Cauchy.

d. Jika $q\left(y, u_{n}\right) \leq \alpha_{n}$ untuk setiap $n \in \mathbb{N}$ maka $\left\{u_{n}\right\}$ barisan Cauchy.

Berikut adalah definisi dari pemetaan yang lebih umum dari pemetaan kontraksi yaitu kontraksi- $F$ yang diberikan oleh Wardowski [15]. 
Definisi 3. Misalkan $(X, d)$ ruang metrik. Fungsi $T: X \rightarrow X$ disebut kontraksi- $F$ jika terdapat $r>0$ dan $F \in$ $\mathcal{F}$ sehingga

$$
r+F(d(T(u), T(v))) \leq F(d(u, v))
$$

untuk setiap u, $v \in X$ dengan $d(T(u), T(v))>0$, di mana $\mathcal{F}$ adalah koleksi semua fungsi $F: \mathbb{R}^{+} \rightarrow \mathbb{R}$ dan memenuhi:

(F1) $\quad F$ adalah fungsi naik monoton tegas, yaitu jika $a<b$ maka $F(a)<F(b)$;

(F2) Untuk setiap barisan $\left\{a_{n}\right\}$ di $\mathbb{R}^{+}, \lim _{n \rightarrow \infty} a_{n}=0$ jika dan hanya jika $\lim _{n \rightarrow \infty} F\left(a_{n}\right)=-\infty$;

(F3) Terdapat $k \in(0,1)$ sehingga $\lim _{a \rightarrow 0^{+}} a^{k} F(a)=0$.

Definisi 4. Misalkan $(Y, d)$ ruang metrik, pemetaan $T: Y \rightarrow Y$ disebut pemetaan tipe Hardy-Roger kontraksi- $F$ jika terdapat $r>0$ dan $F \in \mathcal{F}$ sehingga

$$
r+F(d(T(u), T(v))) \leq F\left(\begin{array}{c}
\alpha \cdot d(u, v)+\beta \cdot d(u, T(u))+\gamma \cdot d(v, T(v))+\mu \cdot d(u, T(v)) \\
+L \cdot d(v, T(u))
\end{array}\right)
$$

untuk setiap $u, v \in Y$ dengan $d(T(u), T(v))>0$, di mana $\alpha, \beta, \gamma, \mu, L$ adalah bilangan bulat nonnegatif, $\gamma \neq 1$ dan $\alpha+\beta+\gamma+2 \mu=1$.

Selanjutnya akan dibuktikan eksistensi titik tetap dengan menggunakan konsep jarak $-\omega$ pada pemetaan tipe Hardy-Roger kontraksi- $F$ dengan mengambil $L=0$.

Teorema 5. Misalkan $(X . d)$ metrik lengkap dan $T: X \rightarrow X$. Jika terdapat $F \in \mathcal{F}$, jarak- $\omega$ q pada $X$, dan $r>0$ sehingga

(1) $r+F(q(T(u), T(v))) \leq F(\alpha \cdot q(u, v)+\beta \cdot q(u, T(u))+\gamma \cdot q(v, T(v))+\mu \cdot q(u, T(v)))$, untuk setiap $u, v \in X$ dengan $q(T(u), T(v))>0$, di mana $\alpha, \beta, \gamma, \mu \geq 0, \gamma \neq 1$, dan $\alpha+\beta+\gamma+2 \mu=1$, (2) untuk setiap $u, v \in X$ dengan $q(T(u), T(v))>0$ berakibat $q(u, v)>0$,

maka $T$ memiliki titik tetap tunggal $u^{*} \in X$ dan untuk setiap $u \in X$, barisan $\left\{T^{n}(u)\right\}$ konvergen ke $u^{*}$. Lebih lanjut $q\left(u^{*}, u^{*}\right)=0$.

Bukti. Diambil sebarang $x_{0} \in X$. Dibentuk barisan $\left\{x_{n}\right\}$ dengan

$$
x_{1}=T\left(x_{0}\right), x_{2}=T\left(x_{1}\right)=T^{2}\left(x_{0}\right), \ldots, x_{n}=T\left(x_{n-1}\right)=T^{n}\left(x_{0}\right) \text {, untuk setiap } n \in \mathbb{N} \text {. }
$$

Diperhatikan dua kemungkinan berikut.

Kasus 1. Jika terdapat $n \in \mathbb{N} \cup\{0\}$ sehingga $q\left(x_{n}, x_{n+1}\right)=0$, maka $q\left(x_{n+1}, x_{n+2}\right)=0$, sebab andaikan $q\left(x_{n+1}, x_{n+2}\right)>0$ maka berdasarkan (2) diperoleh $q\left(x_{n}, x_{n+1}\right)>0$, kontradiksi. Akibatnya $q\left(x_{n}, x_{n+2}\right) \leq$ $q\left(x_{n}, x_{n+1}\right)+q\left(x_{n+1}, x_{n+2}\right)=0$. Selanjutnya, karena $q\left(x_{n}, x_{n+1}\right)=0$ dan $q\left(x_{n}, x_{n+2}\right)=0$, maka dari Lemma 2 diperoleh $x_{n+1}=x_{n+2}$, atau dengan kata lain $x_{n+1}=T\left(x_{n+1}\right)$.

Kasus 2. Jika $q\left(x_{n}, x_{n+1}\right)>0$ untuk setiap $n \in \mathbb{N}$, dengan memisalkan $q_{n}=q\left(x_{n}, x_{n+1}\right)$ berdasarkan (1) diperoleh

Jadi

$$
\begin{aligned}
r+F\left(q_{n}\right) & =r+F\left(q\left(x_{n}, x_{n+1}\right)\right) \\
& =r+F\left(q\left(T\left(x_{n-1}\right), T\left(x_{n}\right)\right)\right) \\
& \leq F\left(\alpha \cdot q\left(x_{n-1}, x_{n}\right)+\beta \cdot q\left(x_{n-1}, T\left(x_{n-1}\right)\right)+\gamma \cdot q\left(x_{n}, T\left(x_{n}\right)\right)+\mu \cdot q\left(x_{n-1}, T\left(x_{n}\right)\right)\right) \\
& =F\left(\alpha \cdot q\left(x_{n-1}, x_{n}\right)+\beta \cdot q\left(x_{n-1}, x_{n}\right)+\gamma \cdot q\left(x_{n}, x_{n+1}\right)+\mu \cdot q\left(x_{n-1}, x_{n+1}\right)\right) \\
& =F\left(\alpha \cdot q_{n-1}+\beta \cdot q_{n-1}+\gamma \cdot q_{n}+\mu \cdot q\left(x_{n-1}, x_{n+1}\right)\right) \\
& \leq F\left(\alpha \cdot q_{n-1}+\beta \cdot q_{n-1}+\gamma \cdot q_{n}+\mu \cdot\left(q\left(x_{n-1}, x_{n}\right)+q\left(x_{n}, x_{n+1}\right)\right)\right) \\
& =F\left(\alpha \cdot q_{n-1}+\beta \cdot q_{n-1}+\gamma \cdot q_{n}+\mu \cdot\left(q_{n-1}+q_{n}\right)\right) \\
& =F\left((\alpha+\beta+\mu) q_{n-1}+(\gamma+\mu) q_{n}\right) .
\end{aligned}
$$

$$
\begin{aligned}
F\left(p_{n}\right) & \leq F\left((\alpha+\beta+\mu) q_{n-1}+(\gamma+\mu) q_{n}\right)-r \\
& <F\left((\alpha+\beta+\mu) q_{n-1}+(\gamma+\mu) q_{n}\right) .
\end{aligned}
$$

Karena $F$ monoton naik tegas, maka dari (4) diperoleh

$$
\begin{gathered}
q_{n}<(\alpha+\beta+\mu) q_{n-1}+(\gamma+\mu) q_{n} \\
\Rightarrow(1-\gamma-\mu) q_{n}<(\alpha+\beta+\mu) q_{n-1}, \text { untuk setiap } n \in \mathbb{N} .
\end{gathered}
$$


Diperhatikan bahwa $\gamma \neq 1$ dan $\alpha+\beta+\gamma+2 \mu=1$, akibatnya $1-\gamma-\mu=\alpha+\beta+\mu>0$, sehingga

$$
q_{n}<\frac{\alpha+\beta+\mu}{1-\gamma-\mu} q_{n-1}=q_{n-1} \text {, untuk setiap } n \in \mathbb{N} \text {. }
$$

Jadi barisan $\left\{q_{n}\right\}$ turun monoton tegas, karena $\left\{p_{n}\right\}$ terbatas ke bawah oleh 0 , maka terdapat $k \geq 0$ sehingga $\lim _{n \rightarrow \infty} q_{n}=k$.

Selanjutnya akan dibuktikan $k=0$. Karena $q_{n}<q_{n-1}$ dan $\alpha+\beta+\gamma+2 \mu=1$ maka

$$
\begin{aligned}
r+F\left(q_{n}\right) & \leq F\left((\alpha+\beta+\mu) q_{n-1}+(\gamma+\mu) q q_{n}\right) \\
& \leq F\left((\alpha+\beta+\mu+\gamma+\mu) q_{n-1}\right) \\
& =F\left((\alpha+\beta+\gamma+2 \mu) q_{n-1}\right) \\
& =F\left(q_{n-1}\right) .
\end{aligned}
$$

Jadi $F\left(q_{n}\right) \leq F\left(q_{n-1}\right)-r \leq F\left(q_{n-2}\right)-2 r \leq \cdots \leq F\left(q_{0}\right)-n r$, untuk setiap $n \in \mathbb{N}$, atau

$$
F\left(q_{n}\right) \leq F\left(q_{0}\right)-n r, \text { untuk setiap } n \in \mathbb{N} \text {. }
$$

Akibatnya $\lim _{n \rightarrow \infty} F\left(q_{n}\right) \leq-\infty$. Berdasarkan (F2), karena $\lim _{n \rightarrow \infty} F\left(q_{n}\right) \leq-\infty$ maka diperoleh $\lim _{n \rightarrow \infty} p_{n}=0$. Selanjutnya dari (F3), terdapat $k \in(0,1)$ sehinga $\lim _{n \rightarrow \infty} q_{n}^{k} F\left(q_{n}\right)=0$. Dari pertidaksamaan (5) diperoleh

$$
q_{n}^{k} F\left(q_{n}\right)-q_{n}^{k} F\left(q_{0}\right) \leq q_{n}^{k}\left(F\left(q_{0}\right)-n r\right)-q_{n}^{k} F\left(q_{0}\right)=-n r q_{n}^{k} \leq 0 .
$$

Selanjutnya karena $\lim _{n \rightarrow \infty} q_{n}=0$ dan $\lim _{n \rightarrow \infty} q_{n}^{k} F\left(p_{n}\right)=0$, maka jika pertidaksamaan (6) dikenakan limit untuk $n$ menuju tak hingga, akan diperoleh $\lim _{n \rightarrow \infty} n q_{n}^{k}=0$, akibatnya $\lim _{n \rightarrow \infty} n^{\frac{1}{k}} q_{n}=0$. Diperhatikan bahwa $\frac{1}{k}>0$ dan $\lim _{n \rightarrow \infty}\left(\frac{q_{n}}{\frac{1}{\frac{1}{k}}}\right)=0$, karena $\sum_{n=1}^{\infty} \frac{1}{n^{\frac{1}{k}}}$ konvergen, maka berdasarkan uji limit diperoleh $\sum_{n=1}^{\infty} q_{n}$ konvergen. Karena $\sum_{n=1}^{\infty} q_{n}$ konvergen maka

$$
\forall \varepsilon_{1}>0, \exists n_{1} \in \mathbb{N} \text { sehingga } \forall n, m \geq n_{1} \text { berlaku } q\left(x_{n}, x_{m}\right)<\varepsilon_{1} .
$$

Selanjutnya akan dibuktikan $\left\{x_{n}\right\}$ adalah barisan Cauchy. Diambil $\varepsilon_{2}>0$ sebarang, karena $q$ adalah jarak$\omega$, maka terdapat $\delta_{2}>0$ sehingga $\forall u, v, z \in X$ dengan $q(z, u) \leq \delta_{2}$ dan $q(z, v) \leq \delta_{2}$ berakibat $d(u, v) \leq$ $\varepsilon_{2}$. Dari (7) diperoleh terdapat $t_{2} \in \mathbb{N}$ sehingga $\forall n, m \geq t_{2}$ berlaku $q\left(x_{n}, x_{m}\right)<\delta_{2}$. Jadi $q\left(x_{t}, x_{n}\right)<\delta_{2}$ dan $q\left(x_{t}, x_{m}\right)<\delta_{2}$, akibatnya $d\left(x_{n}, x_{m}\right) \leq \varepsilon_{2}$ untuk setiap $n, m \geq t_{2}$. Dengan kata lain $\left\{x_{n}\right\}$ barisan Cauchy.

Diketahui $X$ ruang metrik lengkap, karena $\left\{x_{n}\right\}$ barisan Cauchy, maka terdapat $x^{*} \in X$ sehingga $\lim _{n \rightarrow \infty} x_{n}=$ $x^{*}$. Selanjutnya akan dibuktikan $T\left(x^{*}\right)=x^{*}$. Diambil sebarang $\varepsilon_{3}>0$, karena $p$ adalah jarak- $\omega$, maka terdapat $\delta_{3}>0$ sehingga $\forall u, v, z \in X$ dengan $q(z, u) \leq \delta_{3}$ dan $q(z, v) \leq \delta_{3}$ berakibat $d(u, v) \leq \varepsilon_{3}$. Dari (7) maka terdapat $t_{3} \in \mathbb{N}$ sehingga $\forall n, m \geq t_{3}$ berlaku $q\left(x_{n}, x_{m}\right)<\delta_{3}$. Diambil sebarang $h>t_{3}$, karena $\left\{x_{n}\right\}$ konvergen ke $x$ dan $q\left(x_{h}, \cdot\right)$ semikontinu bawah, maka

$$
q\left(x_{h}, x\right) \leq \liminf _{m \rightarrow \infty} q\left(x_{h}, x_{m}\right) \leq \delta_{3}
$$

Jika $q\left(x_{h}, T\left(x^{*}\right)\right)=0$ maka $q\left(x_{h}, T\left(x^{*}\right)\right) \leq \delta_{3}$, sedangkan jika $q\left(x_{h}, T\left(x^{*}\right)\right)>0$, maka $q\left(x_{h-1}, x\right)>0$. Karena $q\left(x_{h-1}, \dot{)}\right)$ semikontinu bawah, maka

$$
q\left(x_{h}, T\left(x^{*}\right)\right)<q\left(x_{h-1}, x\right) \leq \liminf _{m \rightarrow \infty} q\left(x_{h}, x_{m}\right) \leq \delta_{3} .
$$

Berdasarkan (8) dan (9) diperoleh $d\left(x^{*}, T\left(x^{*}\right)\right) \leq \varepsilon_{3}$. Karena $d\left(x^{*}, T\left(x^{*}\right)\right) \leq \varepsilon_{3}$ untuk sebarang $\varepsilon_{3}>0$, maka $d\left(x^{*}, T\left(x^{*}\right)\right)=0$ atau $T\left(x^{*}\right)=x^{*}$.

Selanjutnya akan dibuktikan $\mathrm{q}\left(x^{*}, x^{*}\right)=0$. Andaikan $q\left(x^{*}, x^{*}\right)>0$, berdasarkan (1) diperoleh

$$
\begin{aligned}
& r+F\left(q\left(x^{*}, x^{*}\right)\right) \leq F\left(\alpha \cdot q\left(x^{*}, x^{*}\right)+\beta \cdot q\left(x^{*}, x^{*}\right)+\gamma \cdot q\left(x^{*}, x^{*}\right)+\mu \cdot q\left(x^{*}, x^{*}\right)\right) \\
\Rightarrow & F\left(q\left(x^{*}, x^{*}\right)\right) \leq r+F\left(q\left(x^{*}, x^{*}\right)\right) \leq F\left((\alpha+\beta+\gamma+\mu) q\left(x^{*}, x^{*}\right)\right),
\end{aligned}
$$

di mana $\alpha+\beta+\gamma+\mu \leq 1$, kontradiksi dengan $F$ naik monoton. Jadi $q\left(x^{*}, x^{*}\right)=0$.

Selanjutnya akan dibuktikan ketunggalan titik tetapnya. Andaikan terdapat $y^{*} \in X$ sehingga $T\left(y^{*}\right)=y^{*}$ dengan $x^{*} \neq y^{*}$. Perhatikan dua kemungkinan berikut.

a. Jika $q\left(x^{*}, y^{*}\right)=0$, maka karena $q\left(x^{*}, x^{*}\right)=0$, akibatnya $x^{*}=y^{*}$, kontradiksi.

b. Jika $q\left(x^{*}, y^{*}\right)>0$, berdasarkan (1) diperoleh 


$$
\begin{aligned}
& r+F\left(q\left(x^{*}, y^{*}\right)\right) \leq F\left(\alpha \cdot q\left(x^{*}, y^{*}\right)+\beta \cdot q\left(x^{*}, x^{*}\right)+\gamma \cdot q\left(y^{*}, y^{*}\right)+\mu \cdot q\left(x^{*}, y^{*}\right)\right) \\
\Rightarrow & F\left(q\left(x^{*}, y^{*}\right)\right) \leq r+F\left(q\left(x^{*}, y^{*}\right)\right) \leq F\left((\alpha+\mu) q\left(x^{*}, y^{*}\right)\right),
\end{aligned}
$$

di mana $(\alpha+\mu) \leq 1$, kontradiksi dengan $F$ naik monoton. Jadi $q\left(x^{*}, y^{*}\right)=0$, kontradiksi.

Jadi dapat disimpulkan bahwa $T$ memiliki titik tetap tunggal.

Diperhatikan bahwa kondisi (2) pada Teorema 5 akan selalu berlaku jika jarak- $\omega$ adalah metrik, yaitu jika $d(T(u), T(v))>0$ maka $T(u) \neq T(v)$ sehingga $u \neq v$, akibatnya $d(u, v)>0$. Berikut adalah akibat dari Teorema 5.

Akibat 6. Misalkan (X.d) ruang metrik lengkap dan $T: X \rightarrow X$. Jika terdapat $F \in \mathcal{F}$ pada $X$, dan $r>0$ sehingga

$$
r+F(d(T(u), T(v))) \leq F(\alpha \cdot d(u, v)+\beta \cdot d(u, T(u))+\gamma \cdot d(v, T(v))+\mu \cdot d(u, T(v))),
$$

untuk setiap $u, v \in X$ dengan $d(T(u), T(v))>0$, di mana $\alpha, \beta, \gamma, \mu \geq 0, \gamma \neq 1$, dan $\alpha+\beta+\gamma+2 \mu=1$, maka T memiliki titik tetap tunggal $u^{*} \in X$ dan $\forall u \in X$ berlaku $\lim _{n \rightarrow \infty} T^{n}(u)=u^{*}$.

Berikut adalah akibat dari teorema 5 dan merupakan sifat yang telah dibuktikan oleh Batra dan Vashishta [4].

Akibat 7. Misalkan $(X . d)$ ruang metrik lengkap dan $T: X \rightarrow X$. Jika terdapat $F \in \mathcal{F}$, jarak- $\omega$ q pada $X$, dan $r>0$ sehingga

(10) $r+F(q(T(u), T(v))) \leq F(q(u, v))$, untuk setiap $u, v \in X$ dengan $q(T(u), T(v))>0$,

(11) untuk setiap $u, v \in X$ dengan $q(T(u), T(v))>0$ berakibat $q(u, v)>0$,

maka $T$ memiliki titik tetap tunggal $u^{*} \in X$ dan $\forall u \in X$ berlaku $\lim _{n \rightarrow \infty} T^{n}(u)=u^{*}$. Lebih lanjut $q\left(u^{*}, u^{*}\right)=$ 0 .

Teorema berikut telah dibuktikan oleh Wardowski [15] yang dapat juga dibuktikan melalui akibat dari Teorema 5.

Akibat 8. Misalkan $(X . d)$ ruang metrik lengkap dan $T: X \rightarrow X$. Jika terdapat $F \in \mathcal{F}$ pada $X$, dan $r>0$ sehingga

$$
r+F(d(T(u), T(v))) \leq F(d(u, v))
$$

untuk setiap $u, v \in X$ dengan $d(T(u), T(v))>0$, maka $T$ memiliki titik tetap tunggal $u^{*} \in X$ dan $\forall u \in X$ berlaku $\lim _{n \rightarrow \infty} T^{n}(u)=u^{*}$.

\section{KESIMPULAN}

Berdasarkan hasil pembuktian teorema di atas, dapat disimpulkan bahwa dengan menggunakan konsep jarak- $\omega$ pada pemetaan tipe Hardy-Roger kontraksi- $F$ di ruang metrik lengkap, maka pemetaan tersebut memiliki titik tetap tunggal dengan mengambil $L=0$ dan memberi syarat tambahan jika $q(T(u), T(v))>0$ maka berakibat $q(u, v)>0$ untuk setiap $u, v \in X$ di mana syarat ini selalu berlaku jika yang digunakan adalah metrik. Karena setiap metrik merupakan jarak- $\omega$, maka diperoleh beberapa akibat yang diperoleh dengan mengganti jarak- $\omega$ dengan metrik, di antaranya adalah teorema yang telah dibuktikan oleh Wardowski. Masih banyak jenis pemetaan lain pada ruang metrik yang telah dibuktikan eksistensi titik tetapnya, sehingga dapat diteliti lebih lanjut dengan menggunakan konsep jarak- $\omega$ mengingat jarak- $\omega$ lebih umum dari metrik.

\section{DAFTAR PUSTAKA}

[1] Abbas, M., Ali, B., \& Romaguera, S. (2013). Fixed and periodic points of generalized contractions in metric spaces. Fixed Point Theory Appl, 243. 
[2] Abbas, M., Ali, B., \& Romaguera, S. (2014). Generalized Contractions and Invariant Approximation Result on Nonconvex Subsets of Normed Spaces. Abstr. Appl. Anal, 391952.

[3] Almezel, S., Ansari, Q. H., \& Khamsi, M. A. (2014). Topics in fixed point theory. USA: Springer.

[4] Batra, R., \& Vashishta, S. (2013). Fixed point theorem for F $\omega$-contractions in complete metric spaces. Journal Nonlinear Analysis and Application, 221.

[5] Batra, R., Vashishta, S., \& Kumar, R. (2014). Coincidense point theorem for a new type of contraction on metric spaces. Int. J. Math. Anal, 8, 1315-1320.

[6] Cosentino, V., \& Vetro , P. (2014). Fixed point result for F-contractive mappings of Hardy-Roger-Type. Filomat, 28, 715722.

[7] Edelstein, M. (1962). On fixed and periodic points under contractive mappings. J. Lond. Math. Soc, 37: 74-79.

[8] Kada, O., Suzuki, T., \& Takahashi, W. (1996). Non convex minimization theorems and fixed point theorems in complete metric spaces. Math. Japan, 44: 381-391.

[9] Pasangka, I. G. (2015). Teorema titik tetap terkait jarak- $\omega$. Yogyakarta: Tesis UGM.

[10] Piri, H., \& Kumam , P. (2014). Some fixed point theorems concerning F-contractions in complete metric spaces. Fixed Point Theory Appl, 210

[11] Popescu, O., \& Stan, G. (2020). Two fixed point theorems concerning F-contraction in complete metric spaces. Symmetry, 12(1): 58

[12] Reich, S. (1971). Some remarks concerning contraction mappings. Can. Math. Bull, 14, 121-124.

[13] Secelean, N. (2013). Iterated function system consisting of F-contraction. Fixed Point Theory Appl, 277.

[14] Suzuki, T., \& Takahashi, W. (1996). Fixed point theorems and characterizations of metric completeness. Topology Method in Nonlinear Analysis, 8, 371-382.

[15] Wardowski, D. (2012). Fixed point of a new type of contractive mappings in complete metric space. Fixed Point Theory Appl, 94. 